\title{
Comparison of responses to Ovsynch between Holstein-Friesian and Swedish Red cows
}

\author{
A. Keskin, ${ }^{\star}$ G. Yilmazbas-Mecitoglu, ${ }^{\star}$ A. Gumen, ${ }^{*}$ E. Karakaya, ${ }^{*}$ Y. Celik, $\dagger$ H. Okut, $\neq$ and M. C. Wiltbank ${ }^{1}$ \\ *Department of Obstetrics and Gynecology, Faculty of Veterinary Medicine, University of Uludag, Turkey 16059 \\ †Tarfas Company, Bursa, Turkey 16190 \\ łBiometry of Genetics, Faculty of Agriculture, University of Yuzuncu Yil, Turkey 65080 \\ §Department of Dairy Science, University of Wisconsin-Madison 53706
}

\begin{abstract}
The Ovsynch protocol was designed to synchronize ovulation, thereby allowing timed artificial insemination (TAI) of all cows without detection of estrus. However, the effectiveness of Ovsynch in different breeds of dairy cows has not been previously compared. The aim of this study was to compare the response to Ovsynch in cycling lactating Holstein-Friesian (HF) and Swedish Red (SR) dairy cows. A total of 495 cyclic cows ( $\mathrm{n}=$ $347 \mathrm{HF}, \mathrm{n}=148 \mathrm{SR}$ ) were housed together and treated with Ovsynch $\left(\mathrm{GnRH}-7 \mathrm{~d}-\mathrm{PGF}_{2 \alpha}-56 \mathrm{~h}-\mathrm{GnRH}\right.$ - 16 to $18 \mathrm{~h}$ - TAI). Ovulatory responses, synchronization rate, maximal follicle size at the time of $\mathrm{AI}$, and percentage of pregnant cows per $\mathrm{AI}(\mathrm{P} / \mathrm{AI}$ at 31 and $62 \mathrm{~d}$ after AI) were compared between breeds. Ultrasonography was performed during Ovsynch at first $\mathrm{GnRH}, \mathrm{PGF}_{2 \alpha}$, at time of $\mathrm{AI}$, and $7 \mathrm{~d}$ after AI. Ovulatory response and synchronization rate were similar in HF versus SR cows (60.2 vs. $62.2 \%$; 88.4 vs. $88.5 \%$, respectively). Cows that ovulated to the first GnRH of Ovsynch had smaller follicle size at AI $(15.9 \pm 0.1 \mathrm{vs}$. $16.4 \pm 0.2 \mathrm{~mm}$ ). Maximal follicle size at AI was greater for $\mathrm{HF}(16.4 \pm 2.2 \mathrm{~mm})$ than SR $(15.5 \pm 2.3 \mathrm{~mm})$ cows. The $\mathrm{P} / \mathrm{AI}$ was greater for $\mathrm{SR}$ than $\mathrm{HF}$ cows at the 62 -d pregnancy diagnosis ( 56.1 vs. $46.1 \%$ ). In addition, pregnancy loss between 31 and $62 \mathrm{~d}$ of pregnancy was greater in HF $(10.1 \%)$ than SR $(3.5 \%)$ cows. Fertility was less in HF cows during the hot season (57.7 in cold vs. $38.1 \%$ in the hot season), whereas such a decrease was not observed in SR (60.0 in cold vs. $53.5 \%$ in the hot season) cows. Thus, although the GnRH treatments of Ovsynch were equally effective in SR and HF cows, pregnancy outcomes (P/AI at d 62 and pregnancy survival) were greater in $\mathrm{SR}$ than $\mathrm{HF}$ cows, and $\mathrm{P} / \mathrm{AI}$ in SR cows was not compromised during the hot season as was found for HF cows.
\end{abstract}

Received June 30, 2010.

Accepted November 17, 2010.

${ }^{1}$ Corresponding author: wiltbank@wisc.edu
Key words: breed, dairy cow, Ovsynch, reproduction

\section{INTRODUCTION}

Timed artificial insemination (TAI) programs have become important tools for reproductive management on many commercial dairy farms (Pursley et al., 1997; Rabiee et al., 2005; Souza et al., 2008). Many of the TAI programs are based on the original Ovsynch protocol that can be used to synchronize time of ovulation at first and subsequent $\mathrm{AI}$ in lactating dairy cows (Pursley et al., 1997). Numerous research reports are available comparing Ovsynch, modifications of Ovsynch, and various other reproductive management strategies. A meta-analysis done in 2005 found 71 trials in 53 research publications with sufficient experimental details for inclusion in the analysis (Rabiee et al., 2005). Overall, no differences were detected between Ovsynch and other reproductive management strategies; however, the variation in conception rates between herds (Jemmeson, 2000) and between trials was substantial (Rabiee et al., 2005).

The response to each hormone administration during the Ovsynch protocol can dramatically alter success of the program. Substantial variation exists in the percentage of cows that ovulate in response to the first $\mathrm{GnRH}$ of Ovsynch depending on various factors particularly presynchronization strategy (Bello et al., 2006; Souza et al., 2008; Galvão and Santos, 2010). Generally, greater fertility is found in cows that ovulate to the first GnRH of Ovsynch compared with cows that do not ovulate to the first GnRH (Gümen et al., 2003; Bello et al., 2006; Galvão and Santos, 2010). Response to $\mathrm{PGF}_{2 \alpha}$ also is critical for Ovsynch success. Cows with greater concentrations of progesterone near AI, indicating a lack of complete luteolysis, have much lower fertility (Moreira et al., 2001; Souza et al., 2008; Galvão and Santos, 2010).

Several studies found effects of various physiological factors on fertility following Ovsynch. One of the most critical factors has been the cyclicity status of cows at 
the start of Ovsynch. Ovulatory response to first GnRH and synchronization rate to Ovsynch were greater in noncycling than cycling dairy cows (Gümen et al., 2003; Karakaya et al., 2009), although fertility was lower in the cows that were noncycling before Ovsynch (Gümen et al., 2003). Other cow factors that alter success with Ovsynch include stage of the estrous cycle at the start of Ovsynch, DIM, parity, and service number (Bello et al., 2006; Souza et al., 2008; Galvão and Santos, 2010). For example, primiparous cows generally have enhanced fertility compared with multiparous cows following Ovsynch (Gümen et al., 2003; Tenhagen et al., 2003; Souza et al., 2008). In addition, synchronization rate to Ovsynch and percentage pregnant per AI (P/AI) were greater when cycling cows began Ovsynch on d 5 to 12 of the cycle compared with earlier or later times (Vasconcelos et al., 1999; Moreira et al., 2001; Bello et al., 2006). Several presynchronization programs have been developed to optimize the cycle stage at the start of Ovsynch (Moreira et al., 2001; Bello et al., 2006; Souza et al., 2008).

It seems likely that dairy cow breed could have substantial effects on responses to Ovsynch, although we have been unable to locate any studies that directly compared the response of different dairy breeds to the Ovsynch protocol. Previous studies evaluated Ovsynch in various breeds of beef cattle (Geary et al., 2001; Lamb et al., 2010), in dairy cattle under grazing conditions (Cordoba and Fricke, 2001; Cavestany et al., 2007) and with different breeds of sires (Pegorer et al., 2007), and in buffalo (de Araujo Berber et al., 2002). Because of the lack of direct comparisons between breeds, this study was undertaken to compare the response to Ovsynch in Holstein-Friesian and Swedish Red dairy cattle. To eliminate the effect of cyclicity status, only cows that were cycling were used in this study.

\section{MATERIALS AND METHODS}

\section{Cows, Housing, and Management}

This experiment was conducted on a commercial dairy herd in the South Marmara region, Bursa, Turkey. The dairy herd consisted of approximately 1,000 lactating cows comprising purebred Holstein-Friesian (HF; approximately $65 \%$ of herd; original HolsteinFriesian cows imported from Sweden in May 2005) and purebred Swedish Red (SR; approximately 35\% of herd; originally imported from Sweden in May 2005) cows. All breedings were by AI using commercial semen from HF ( $>10$ sires) and SR (4 sires) sires, used on the same breed of dairy cows. Both breeds of cows were housed together in the same freestall barns, and all pens had fans and sprinklers that were activated during the hotter months of the year. All cows were milked 3 times daily. Mean milk production of the herd was $9,880 \pm 69.7 \mathrm{~kg}(305 \mathrm{~d})$ per cow. Cows were fed a TMR formulated based on NRC recommendations (NRC, 2001). Daily milk yield, reproductive, health, and management records for each cow were collected on the Alpro 2000 system (DeLaval, Tumba, Sweden). Average milk production for each cow was recorded during the $7 \mathrm{~d}$ before and $7 \mathrm{~d}$ after AI (14 d average).

To determine the effects of season on fertility, daily average temperature was determined throughout the experiment using temperature records from the Turkish State Meteorological Services (2009). The average temperature during each month was determined and based on these data; the hot season was designated as May to September and the cold season was designated from October to April. The mean daily temperature for the hot and cold periods was $21.8 \pm 3.8^{\circ} \mathrm{C}$ and $9.4 \pm$ $2.7^{\circ} \mathrm{C}$, respectively. All protocols involving cows used in this research were approved by the Lalahan Livestock Central Research Institute Animal Care Committee.

\section{Examinations}

A total of 495 cycling lactating dairy cows was included ( $\mathrm{n}=347 \mathrm{HF}$ and $\mathrm{n}=148 \mathrm{SR}$ ) in the study. Before including cows, ultrasound evaluation of their ovaries was performed to determine the cyclic status of each cow. The ultrasonographic examinations were performed with a Honda HS 2000 equipped with a 7.5$\mathrm{MHz}$ transducer (Honda, Tokyo, Japan). The ovaries were evaluated and the presence of a corpus luteum was used as evidence of cyclicity. The ovaries were evaluated again $7 \mathrm{~d}$ later, and any cow without a corpus luteum at either of these examinations was designated as anovular and was not used. In addition, any cows with evidence of uterine or vaginal infection were not used.

Healthy, nonpregnant, cycling cows that were more than 60 DIM were selected for the study and treated with the Ovsynch protocol. A total of 213 cows had AI at first service. Any cows that were not pregnant at pregnancy diagnosis and had a corpus luteum were used in the study. A total of 282 cows had AI at second or later services during the experiment. During the experimental period, any cows that were not pregnant at the pregnancy diagnosis and were cycling were included. The first GnRH (Buserelin acetate, i.m., 10 $\mu \mathrm{g}$, Receptal, Intervet, Istanbul, Turkey) of Ovsynch was administrated on the day the cows were selected without regard to stage of the estrous cycle. Seven days after GnRH, PGF ${ }_{2 \alpha}$ (Cloprostenol, $500 \mu \mathrm{g}$, i.m., Estrumate, CEVA-DIF, Istanbul, Turkey) was administered. A second GnRH treatment (Buserelin acetate, $10 \mu \mathrm{g}$, 
Receptal) was administered $56 \mathrm{~h}$ after $\mathrm{PGF}_{2 \alpha}$ and all cows had TAI 16 to $18 \mathrm{~h}$ after the final GnRH treatment.

Ovarian ultrasound was performed on the day of the first $\mathrm{GnRH}$ administration and all follicles $>6 \mathrm{~mm}$ in diameter and the location of any corpora lutea were recorded. A second ovarian ultrasound was performed $7 \mathrm{~d}$ later to determine whether cows ovulated to the first GnRH treatment. Ovulation to first GnRH treatment was designated if a new corpus luteum was found in an ovarian location corresponding to a dominant follicle observed during the first examination. A third ultrasound examination was performed at the time of $\mathrm{AI}$, and the follicular diameter of the potential ovulatory follicle(s) was obtained by averaging perpendicular measurements of the cross-sectional diameter for each follicle. A fourth ultrasound examination was performed $7 \mathrm{~d}$ after AI. Ovulation to the second GnRH treatment was determined by the presence of a new corpus luteum (CL) on the ovary at an ovarian position corresponding to the dominant follicle(s) present at the time of AI. Pregnancy diagnosis was performed $31 \mathrm{~d}$ after AI using ultrasonography. A second pregnancy diagnosis was performed $62 \mathrm{~d}$ after AI using ultrasonography (presence of a fetus). A BCS was determined for all cows at the time of the first GnRH treatment of Ovsynch using a 5 -point $(1=$ thin to $5=$ fat $)$ scoring system (Ferguson et al., 1994).

\section{Statistical Analyses}

All statistical procedures were performed using the computational software of SAS (release 9.2, SAS Institute Inc., Cary, NC). Percentage pregnant per AI was defined as the number of pregnant cows divided by the number of cows that received TAI. Statistical models were constructed that included breed (HF or SR), parity of cows (primiparous or multiparous), service number (first or later services), and season (hot or cold season).

Binomial responses were analyzed with the PROC FREQ procedure to compare differences between breeds in parity, service number, ovulatory response to the first $\mathrm{GnRH}$ of Ovsynch, P/AI at the first (31 d) and second (62 d) pregnancy diagnosis, and pregnancy loss between first and second pregnancy diagnosis. In addition, $\mathrm{P} / \mathrm{AI}$ by parity was evaluated for the 2 breeds by the PROC FREQ procedure. The PROC GLM procedure was performed to compare milk production, DIM, BCS, and follicle size at the time of AI between breeds and the effect of milk production, season, parity, and service number on follicle size in the 2 different breeds. The PROC LOGISTIC procedure was used to analyze the following: the effect of ovulatory response
Table 1. Mean lactation number, average DIM, BCS, and milk production in Holstein-Friesian and Swedish Red cows

\begin{tabular}{lccl}
\hline Item & Holstein-Friesian & Swedish Red & $P$-value \\
\hline Mean lactation number & $2.2 \pm 0.05$ & $2.6 \pm 0.07$ & 0.001 \\
Average DIM & $127.2 \pm 3.9$ & $112.7 \pm 5.9$ & 0.04 \\
BCS & $2.76 \pm 0.02$ & $2.89 \pm 0.02$ & 0.001 \\
Milk production $(\mathrm{kg} / \mathrm{d})$ & $40.3 \pm 0.46$ & $34.9 \pm 0.70$ & 0.001 \\
\hline
\end{tabular}

on pregnancy rates; the effect of ovulatory response on follicle size at the time of AI; the effect of milk production, DIM, BCS, follicle size at the time of AI, parity, and service number on ovulatory response and on $\mathrm{P} / \mathrm{AI}$ between breeds; the effect of season on P/AI (31- and 62-d pregnancy diagnoses); and interaction between breed, season, and parity. A forward stepwise selection procedure was used to construct the final model, and differences with $P<0.05$ were considered significant.

\section{RESULTS}

Although all nonpregnant, cycling cows from either breed on this commercial dairy were used, breeds differed in mean lactation number, DIM, BCS, and milk production (Table 1 ). The SR cows had more previous lactations (+0.4 lactations), fewer DIM $(-14.5 \mathrm{~d})$, greater BCS $(+0.13 \mathrm{BCS})$, and lower milk production $(-5.4 \mathrm{~kg})$ than the HF cows.

The effect of breed on ovulatory response to first $\mathrm{GnRH}$, ovulatory response to second $\mathrm{GnRH}, \mathrm{P} / \mathrm{AI}$ at the 2 pregnancy diagnoses, and pregnancy loss was compared (Table 2). The percentage of cows that ovulated to the first GnRH treatment was similar $(P=0.68)$ between HF and SR cows. Milk production, DIM, BCS, service number, and parity had no effect on ovulatory response to the first GnRH treatment. Similarly, the percentage of cows that ovulated to the second $\mathrm{GnRH}$ treatment was similar $(P=0.98)$ between breeds.

The percentage of cows $\mathrm{P} / \mathrm{AI}$ at the first pregnancy diagnosis (31 d after AI) was $58.1 \%$ for the SR and $51.2 \% \mathrm{HF}$ cows $(51.2 \% ; P=0.16)$. At the second pregnancy diagnosis (62 d after AI), the SR cows had greater $(P=0.04) \mathrm{P} / \mathrm{AI}$ than HF cows. The pregnancy loss between the 31- and the 62-d pregnancy diagnoses was greater $(P=0.04)$ for the HF than SR cows (Table 2).

No overall effect of follicle size on P/AI was observed. The analyses of $\mathrm{P} / \mathrm{AI}$ at either the 31- or 62-d pregnancy diagnoses did not indicate an effect of number of services, DIM, or milk production on $\mathrm{P} / \mathrm{AI}$ when analyzed within or between breeds.

Interactions of parity and breed were not significant at $31-(P=0.16)$ and $62-\mathrm{d}(P=0.37)$ pregnancy diagnoses; however, effects of breed on $\mathrm{P} / \mathrm{AI}$ were only 
Table 2. Ovulatory response to GnRH treatments, percentage pregnant per AI, and pregnancy loss in Holstein-Friesian and Swedish Red cows

\begin{tabular}{|c|c|c|c|}
\hline Item & Holstein-Friesian & Swedish Red & $P$-value \\
\hline Ovulation to second GnRH of Ovsynch, \% (n/n) & $88.4(307 / 347)$ & $88.5(131 / 148)$ & 0.98 \\
\hline Pregnant/AI at 31-d pregnancy diagnosis, $\%(\mathrm{n} / \mathrm{n})$ & $51.2(178 / 347)$ & $58.1(86 / 148)$ & 0.16 \\
\hline Pregnancy loss, \% (n/n) & $10.1(18 / 178)$ & $3.5(3 / 86)$ & 0.04 \\
\hline
\end{tabular}

observed in older cows (Table 3 ). In primiparous cows, breed had no effect at either the 31- $(P=0.60)$ or $62-\mathrm{d}$ $(P=0.93)$ pregnancy diagnoses. In contrast, in multiparous cows, there tended $(P=0.07)$ to be a greater $\mathrm{P} /$ $\mathrm{AI}$ in SR than HF cows at the 31-d pregnancy diagnosis $(\mathrm{SR}=60.2 \%$ vs. $\mathrm{HF}=50.0 \%)$. At the 62 -d pregnancy diagnosis, the $\mathrm{P} / \mathrm{AI}$ was greater $(P=0.03)$ in the $\mathrm{SR}$ $(57.7 \%)$ than the HF $(45.5 \%)$ multiparous cows. Parity did not affect P/AI at either the 31- or the 62-d pregnancy diagnosis in either breed. Pregnancy loss was greater in $\mathrm{HF}$ than $\mathrm{SR}$ primiparous cows $(\mathrm{HF}=12.1$ vs. SR $=0 \% ; P=0.003)$, but not different in multiparous cows $(\mathrm{HF}=8.9$ vs. $\mathrm{SR}=4.1 \% ; P=0.16)$.

An effect of season on $\mathrm{P} / \mathrm{AI}$ was observed at both the $31-(P=0.01)$ and $62-\mathrm{d}(P=0.008)$ pregnancy diagnoses, but no interaction of breed and season on $\mathrm{P} / \mathrm{AI}$ at either the $31-(P=0.22)$ or $62-\mathrm{d}(P=0.17)$ pregnancy diagnoses was found. In the cold season, breeds did not differ at either the $31-(P=0.70)$ or the 62 -d $(P=0.38)$ pregnancy diagnoses (Table 4$)$. In the hot season, there tended $(P=0.08)$ to be greater $\mathrm{P} / \mathrm{AI}$ in $\mathrm{SR}$ than $\mathrm{HF}$ at the 31-d pregnancy diagnosis $(\mathrm{SR}=53.5$ vs. $\mathrm{HF}=38.1 \%)$, and $\mathrm{P} / \mathrm{AI}$ was greater $(P$ $=0.02)$ in $\mathrm{SR}(51.2 \%)$ than $\mathrm{HF}(31.9 \%)$ at the $62-\mathrm{d}$ pregnancy diagnosis (Table 4). In HF cows, there was a greater number of $\mathrm{P} / \mathrm{AI}$ in the cold than the hot season at both the $31-(P=0.001)$ and the $62-\mathrm{d}(P=$ $0.0002)$ pregnancy diagnoses. This seasonal effect on $\mathrm{P} /$ AI was not observed in SR cows. Season did not affect pregnancy loss in HF (cold $=8.1$ vs. hot $=16.3 \% ; P=$ 0.18 ) or in SR (cold $=3.2$ vs. hot $=4.3 \%$ ). No effect of breed on pregnancy loss was observed in either the cold $(P=0.15)$ or hot $(P=0.16)$ season. The 3 -way interaction (breed $\times$ parity $\times$ season) was not significant for the 31- $(P=0.75)$ or 62 -d $(P=0.93)$ pregnancy diagnoses.

The follicle diameter at the time of AI was not altered by DIM, BCS, or season; however, it was affected by breed, parity, and ovulation response to the first GnRH treatment (Table 5). Follicle diameter at the time of AI was greater $(P=0.004)$ for $\mathrm{HF}$ than $\mathrm{SR}$ cows $(+0.9$ $\mathrm{mm})$. The primiparous cows had a smaller $(P=0.005)$ follicle diameter than multiparous cows $(-0.7 \mathrm{~mm})$. The follicle diameter at AI during the hot season was 15.9 $\mathrm{mm}$ compared with $16.2 \mathrm{~mm}$ for the cold season $(-0.3$ $\mathrm{mm} ; P=0.18)$. Cows that ovulated to the first $\mathrm{GnRH}$ treatment had a smaller $(P=0.02)$ follicle diameter at AI than cows that did not ovulate to the GnRH $(-0.5$ $\mathrm{mm}$ ). Milk production had an effect on follicle diameter at AI $(P=0.009)$ such that every $1-\mathrm{kg}$ increase in milk production was associated with a $0.03 \pm 0.01 \mathrm{~mm}$ increase in follicle diameter.

\section{DISCUSSION}

Our results indicated that $\mathrm{HF}$ and SR cows had a similar response to the first and second GnRH treatments of the Ovsynch protocol. The approximately $60 \%$ ovulation incidence to the first $\mathrm{GnRH}$ treatment supports the rate reported in HF cows in some studies (Gümen et al., 2003; Souza et al., 2008; Galvão and Santos, 2010), but was greater than reported in other studies (Navanukraw et al., 2004; Bello et al., 2006). The approximately $88 \%$ ovulation incidence to the second GnRH treatment supported results reported in other studies (Cordoba and Fricke, 2001; Moreira et al., 2001; Gümen et al., 2003) using HF cows. Thus, although substantial breed differences may exist in many

Table 3. The effects of breed [Holstein-Friesian (HF) vs. Swedish Red (SR)] and parity (primiparous vs. multiparous) on percentage pregnant per AI

\begin{tabular}{|c|c|c|c|c|c|c|}
\hline Parity & \multicolumn{2}{|c|}{ 31-d pregnancy diagnosis } & $P$-value & \multicolumn{2}{|c|}{ 62-d pregnancy diagnosis } & $P$-value \\
\hline Primiparous, \% (n/n) & $53.6(66 / 123)$ & $48.0(12 / 25)$ & 0.60 & $47.2(58 / 123)$ & $48.0(12 / 25)$ & 0.93 \\
\hline$P$-value & 0.51 & 0.26 & & 0.77 & 0.37 & \\
\hline
\end{tabular}


Table 4. The effects of breed [Holstein-Friesian (HF) vs. Swedish Red (SR)] and season (cold vs. hot) on percentage pregnant per AI

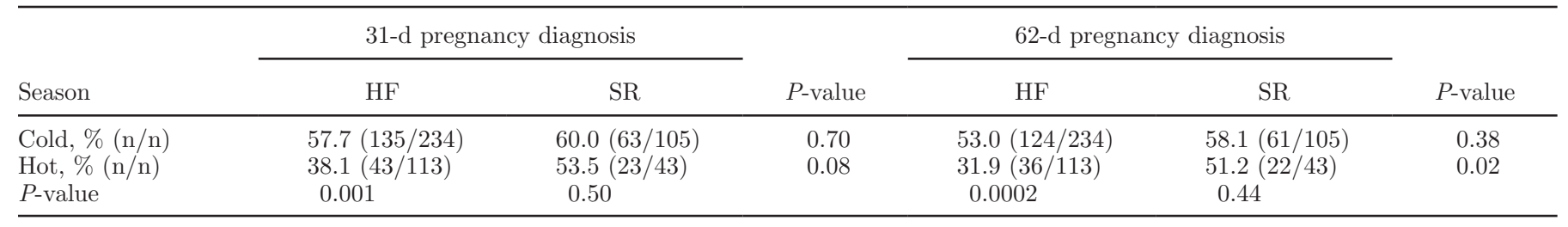

reproductive characteristics, it seems that Ovsynch produces a similar synchronization response in cycling cows of both breeds. Despite this similarity in synchronization responses to Ovsynch, there were substantial breed differences after Ovsynch in follicle size at the time of AI, pregnancy loss, percentage pregnant at the $62-\mathrm{d}$ pregnancy diagnosis, and sensitivity of $\mathrm{P} / \mathrm{AI}$ to hotter weather.

One of the key observations was that breed differences did not reach statistical significance until the later pregnancy diagnosis. This observation highlights the importance of pregnancy loss in the reduced fertility in HF cattle. The SR cattle did not have large pregnancy losses between the 31- and 62-d pregnancy diagnoses $(3.5 \%)$. Pregnancy loss was greater in HF cows (10.1\%), but consistent with pregnancy loss previously reported in HF cows in the US (Vasconcelos et al., 1999; Moreira et al., 2001; Gümen et al., 2003) and Brazil (Pegorer et al., 2007). This larger pregnancy loss was observed in both primiparous and multiparous HF cows and during both the cold and hot seasons in HF cows, although there was some indication of an increase during the hot season (16.3 vs. $8.1 \%$ ). In contrast, pregnancy loss was small in all parities and seasons in SR cows.

An apparent differential sensitivity to hot weather was observed that seemed to underlie the reproductive differences between breeds. The reduced fertility in HF compared with SR cows was only observed during the hot and not the cold season. This breed difference was clearly because of a reduction in fertility during the hot season in HF cows that did not occur in SR cows. Given that all cows were in the same pens and exposed to the same environmental conditions, it seems likely that HF cows have a greater sensitivity to hot weather than SR cows. Differences between breeds in thermal tolerance for many different reproductive traits have been reported (Paula-Lopes et al., 2003; Hernández-Cerón et al., 2004; Eberhardt et al., 2009). Our experimental design did not allow us to determine whether increased susceptibility to the deleterious effects of heat stress in HF cows was because of a breed effect. It is possible that increased response to hot weather in HF cows is primarily related to greater milk production in HF than SR cows. Increased milk production has been related previously to a greater reduction in fertility in HF cows during hot seasons (Lopez-Gatius, 2003). Future studies are needed to differentiate mechanisms producing breed differences in susceptibility to hot weather or heat stress that seem to underlie our observed breed differences in fertility.

The follicle diameter at the time of AI was altered by breed, parity, milk production, and ovulatory response to first GnRH of Ovsynch. The HF cows had a larger follicle diameter at AI than SR cows despite the similarity in responses to first and second $\mathrm{GnRH}$ in the 2 breeds. Cows of either breed that ovulated to the first $\mathrm{GnRH}$ had a smaller follicle diameter than cows that did not ovulate. The effect of follicle size on fertility is somewhat complex and seems to be curvilinear with either too small or too large a follicle size reported at times to reduce fertility compared with an optimal follicle size (13 to $18 \mathrm{~mm}$; Vasconcelos et al., 1999; Tenhagen et al., 2003; Lopes et al., 2007). Yet, the optimal follicle size in the Turkish HF and SR cows used in this study has not yet been determined. Although follicle diameter was smaller in primiparous than multiparous cows, we did not observe an overall effect of parity on fertility. Nevertheless, the breed effects on fertility were unexpectedly only observed in multiparous and not in primiparous cows. Another factor affecting follicle diameter was milk production, with each 1-kg increase in daily milk production increasing preovulatory follicle diameter by $0.03 \mathrm{~mm}$. Ovulatory follicle diameter after

Table 5. The effects of breed [Holstein-Friesian (HF) vs. Swedish Red (SR)], parity, season, and ovulation to first $\mathrm{GnRH}$ on follicle diameter at the time of $\mathrm{AI}$

\begin{tabular}{lcc}
\hline & $\begin{array}{c}\text { Follicle } \\
\text { Item }\end{array}$ & \\
\hline Breed & & $P$-value \\
HF & $16.4 \pm 2.2$ & 0.0004 \\
SR & $15.5 \pm 2.3$ & \\
Parity & $15.6 \pm 2.1$ & 0.005 \\
$\quad$ Primiparous & $16.3 \pm 2.2$ & \\
$\quad$ Multiparous & & \\
Season & $15.9 \pm 2.3$ & \\
$\quad$ Hot & $16.2 \pm 2.2$ & \\
Cold & & \\
Ovulation to first GnRH & $15.9 \pm 0.12$ & \\
$\quad$ Yes & $16.4 \pm 0.16$ & \\
No & & \\
\hline
\end{tabular}


Ovsynch is regulated by complex interactions among multiple factors, with some of these same interactions potentially regulating subsequent fertility in lactating dairy cows.

In conclusion, even though $\mathrm{HF}$ and SR cows responded to Ovsynch similarly, differences between breeds were observed in preovulatory follicle size, fertility, pregnancy loss, and susceptibility to hot weather. Improved understanding of these breed differences may provide insights that could result in improvements in the Ovsynch protocol as well as in other reproductive management programs for different breeds of lactating dairy cows.

\section{ACKNOWLEDGMENTS}

The authors thank Tarfas Co. (Bursa, Turkey) and its staff for their help and use of their herd and facilities. Support also was provided by the Scientific and Technological Research Council of Turkey (TUBITAK) grant No. TOVAG $107 \mathrm{O} 227$.

\section{REFERENCES}

Bello, N. M., J. P. Steibel, and J. R. Pursley. 2006. Optimizing ovulation to first GnRH improved outcomes to each hormonal injection of Ovsynch in lactating dairy cows. J. Dairy Sci. 89:3413-3424.

de Araujo Berber, R. C. A., E. H. Madureira, and P. S. Baruselli. 2002. Comparison of two Ovsynch protocols ( $\mathrm{GnRH}$ versus $\mathrm{LH}$ ) for fixed timed insemination in buffalo (Bubalus bubalis). Theriogenology 57:1421-1430.

Cavestany, D., H. Betancour, J. E. Blanc, C. Lemaire, J. Slavica, F. Moreira, J. Piaggio, and C. Risco. 2007. Reproductive efficiency in grazing lactating dairy cows under programmed reproductive management system. Aust. Vet. J. 85:141-147.

Cordoba, M. C., and P. M. Fricke. 2001. Evaluation of two hormonal protocols for synchronization of ovulation and timed artificial insemination in dairy cows managed in grazing-based dairies. J. Dairy Sci. 84:2700-2708.

Eberhardt, B. G., R. A. Satrapa, C. R. L. Capinzaiki, L. A. Trinca, and C. M. Barros. 2009. Influence of the breed of bull (Bos taurus indicus vs. Bos taurus taurus) and the breed of cow (Bos taurus indicus, Bos taurus taurus and crossbred) on the resistance of bovine embryos to heat. Anim. Reprod. Sci. 114:54-61.

Ferguson, J. D., D. T. Galligan, and N. Thomsen. 1994. Principal descriptors of body condition score in Holstein cows. J. Dairy Sci. $77: 2695-2703$

Galvão, K. N., and J. E. P. Santos. 2010. Factors affecting synchronization and conception rate after the Ovsynch protocol in lactating Holstein dairy cows. Reprod. Domest. Anim. 45:439-446.

Geary, T. W., R. R. Salverson, and J. C. Whittier. 2001. Synchronization of ovulation using $\mathrm{GnRH}$ or hCG with the CO-Synch protocol in suckled beef cows. J. Anim. Sci. 79:2536-2541.

Gümen, A., J. N. Guenther, and M. C. Wiltbank. 2003. Follicular size and response to Ovsynch versus detection of estrus in anovular and ovular lactating dairy cows. J. Dairy Sci. 86:3184-3194.
Hernández-Cerón, J., C. C. Chase, and P. J. Hansen. 2004. Differences in heat tolerance between preimplantation embryos from Brahman, Romosinuano, and Angus Breeds. J. Dairy Sci. 87:53-58.

Jemmeson, A. 2000. Synchronizing ovulation in dairy cows with either two treatments of gonadotropin-releasing hormone and one of prostaglandin, or two treatments of prostaglandin. Aust. Vet. J. 78:108-111.

Karakaya, E., G. Yilmazbaş, A. Keskin, V. Mutis, and A. Gümen. 2009. Comparing of response to Ovsynch protocol in ovular and anovular lactating dairy cows. Reprod. Domest. Anim. 44(Suppl. 2):87. (Abstr.)

Lamb, G. C., C. R. Dahlen, J. E. Larson, G. Maquezini, and J. S. Stevenson. 2010. Control of the estrous cycle to improve fertility for fixed-timed artificial insemination in beef cattle: A review. J. Anim. Sci. 88:181-192.

Lopes, A. S., S. T. Butler, R. O. Gilbert, and W. R. Butler. 2007. Relationship of pre-ovulatory follicle size, estradiol concentrations and season to pregnancy outcome in dairy cows. Anim. Reprod. Sci. 99:34-43.

Lopez-Gatius, F. 2003. Is fertility declining in dairy cattle? A retrospective study in northeastern Spain. Theriogenology 60:89-99.

Moreira, F., C. Orlandi, C. A. Risco, R. Mattos, F. Lopes, and W. W. Thatcher. 2001. Effects of presynchronization and bovine somatotropin on pregnancy rates to a timed artificial insemination protocol in lactating dairy cows. J. Dairy Sci. 84:1646-1659.

National Research Council. 2001. Nutrient Requirements of Dairy Cattle. 7th rev. ed. Natl. Acad. Sci., Washington, D.C.

Navanukraw, C., D. A. Redmer, L. P. Reynolds, J. D. Kirsch, A. T. Grazul-Bliska, and P. M. Fricke. 2004. A modified presynchronization protocol improves fertility to timed artificial insemination in lactating dairy cows. J. Dairy Sci. 87:1551-1557.

Paula-Lopes, F. F., C. C. Chase, Y. M. Al-Katanani, C. E. Krininger, R. M. Rivera, S. Tekin, A. C. Majewski, O. M. Ocon, T. A. Olson, and P. J. Hansen. 2003. Genetic divergence in cellular resistance to heat shock in cattle: Differences between breeds developed in temperate versus hot climates in responses of preimplantation embryos, reproductive tract tissues and lymphocytes to increased culture temperatures. Reproduction 125:285-294.

Pegorer, M. F., J. L. M. Vasconcelos, L. A. Trinca, P. J. Hansen, and C. M. Barros. 2007. Influence of sire and sire breed (Gir versus Holstein) on establishment of pregnancy and embryonic loss in lactating Holstein cows during summer heat stress. Theriogenology 67:692-697.

Pursley, J. R., M. R. Kosorok, and M. C. Wiltbank. 1997. Reproductive management of lactating dairy cows using synchronization of ovulation. J. Dairy Sci. 80:301-306.

Rabiee, A. R., I. J. Lean, and M. A. Stevenson. 2005. Efficacy of Ovsynch program on reproductive performance in dairy cattle: A meta-analysis. J. Dairy Sci. 88:2754-2770.

Souza, A. H., H. Ayres, R. M. Ferreira, and M. C. Wiltbank. 2008. A new presynchronization system (Double-Ovysnch) increases fertility at first postpartum timed AI in lactating dairy cows. Theriogenology 70:208-215.

Tenhagen, B. A., M. Wittke, M. Drillich, and W. Heuwieser. 2003. Timing of ovulation and conception rate in primiparous and multiparous cows after synchronization of ovulation with $\mathrm{GnRH}$ and $\mathrm{PGF}_{2 \alpha}$. Reprod. Domest. Anim. 38:451-454.

Turkish State Meteorological Services. 2009. Accessed Nov. 16, 2009. http://www.dmi.gov.tr/index.aspx.

Vasconcelos, J. L. M., R. W. Silcox, G. J. M. Rosa, J. R. Pursley, and M. C. Wiltbank. 1999. Synchronization rate, size of the ovulatory follicle, and pregnancy rate after synchronization of ovulation beginning on different days of the estrous cycle in lactating dairy cows. Theriogenology 52:1067-1078. 